\title{
New Frontiers in Gut Nutrient Sensor Research: Nutrient Sensors in the Gastrointestinal Tract: Modulation of Sweet Taste Sensitivity by Leptin
}

\author{
Nao Horio ${ }^{1}$, Masafumi Jyotaki ${ }^{1}$, Ryusuke Yoshida $^{1}$, Keisuke Sanematsu ${ }^{1}$, Noriatsu Shigemura ${ }^{1}$, \\ and Yuzo Ninomiya ${ }^{1, *}$ \\ ${ }^{1}$ Section of Oral Neuroscience, Kyushu University, Graduate School of Dental Sciences, \\ 3-1-1 Maidashi, Higashi-ku, Fukuoka 812-8582, Japan
}

Received April 2, 2009; Accepted April 21, 2009

\begin{abstract}
The ability to perceive sweet compounds is important for animals to detect an external carbohydrate source of calories and has a critical role in the nutritional status of animals. In mice, a subset of sweet-sensitive taste cells possesses leptin receptors. Increase of plasma leptin with increasing internal energy storage in the adipose tissue suppresses sweet taste responses via this receptor. The data from recent studies indicate that leptin may also act as a modulator of sweet taste sensation in humans with a diurnal variation in sweet sensitivity. The plasma leptin level and sweet taste sensitivity are proposed to link with post-ingestive plasma glucose level. This leptin modulation of sweet taste sensitivity may influence an individual's preference, ingestive behavior, and absorption of nutrients, thereby playing important roles in regulation of energy homeostasis.
\end{abstract}

Keywords: sweet taste, leptin, modulation, energy homeostasis, gastrointestinal tract

\section{Introduction}

The sense of taste is important for animals to evaluate the quality of food components. Mammals discriminate the five taste modalities bitter, sweet, umami, sour, and salty by using different taste sensors. For example, bitter taste, detected by the Taste receptor type 2 family (T2Rs) (1), causes aversive actions in animals and humans to protect the organism from ingesting toxic substances, whereas sweet taste, detected by heterodimers of Taste receptor type 1, member 2 (T1R2) and member 3 (T1R3) (2), is attractive, indicating a caloric energy source.

Leptin, the product of the obese gene $(o b)$, is a hormone primarily produced in adipose cells. It regulates food intake, energy expenditure, and body weight mainly via activation of the hypothalamic leptin receptor. Leptin is thought to promote weight loss, at least in rodents, by suppressing appetite and stimulating metabolism (3). Mutant mice that have defects in either leptin or the leptin receptor, such as $o b / o b$ and $d b / d b$ mice, are hyperphagic,

*Corresponding author. yuninom@dent.kyushu-u.ac.jp

Published online in J-STAGE

doi: 10.1254/jphs.09R07FM massively obese, and diabetic $(3,4)$. Recent studies have shown that sweet-sensitive cells also possess the leptin receptor $(5-7)$. Increase of plasma leptin level leads to reduction of taste nerve responses and behavioral preference for sweet compounds. This paper summarized the data from recent studies in mice and humans that further addressed such leptin modulation of sweet taste sensitivity and its role in the regulation of energy homeostasis.

\section{Sweet-sensitive cell as a sensor for external caloric and thermal energy sources}

A major advance in our understanding of sweet taste signaling is the discovery of two G-protein-coupled receptors, T1R2 and T1R3, which dimerize to form a sweet taste receptor (T1R2+T1R3) that can bind a broad array of sweet compounds including external caloric energy sources (2). As shown in Fig. 1, binding of sweet compounds to T1R2+T1R3 leads to activation and dissociation of the subunits of the coupled heterotrimeric $\mathrm{G}$ protein, probably gustducin (Ggust) (8) but possibly other $\mathrm{G}$ proteins too. The dissociated $\beta \gamma$ subunits of the Ggust activate phospholipase C (PLC $\beta 2$ ), which hydrolyzes phosphatidylinositol bisphosphate $\left(\mathrm{PIP}_{2}\right)$ into 


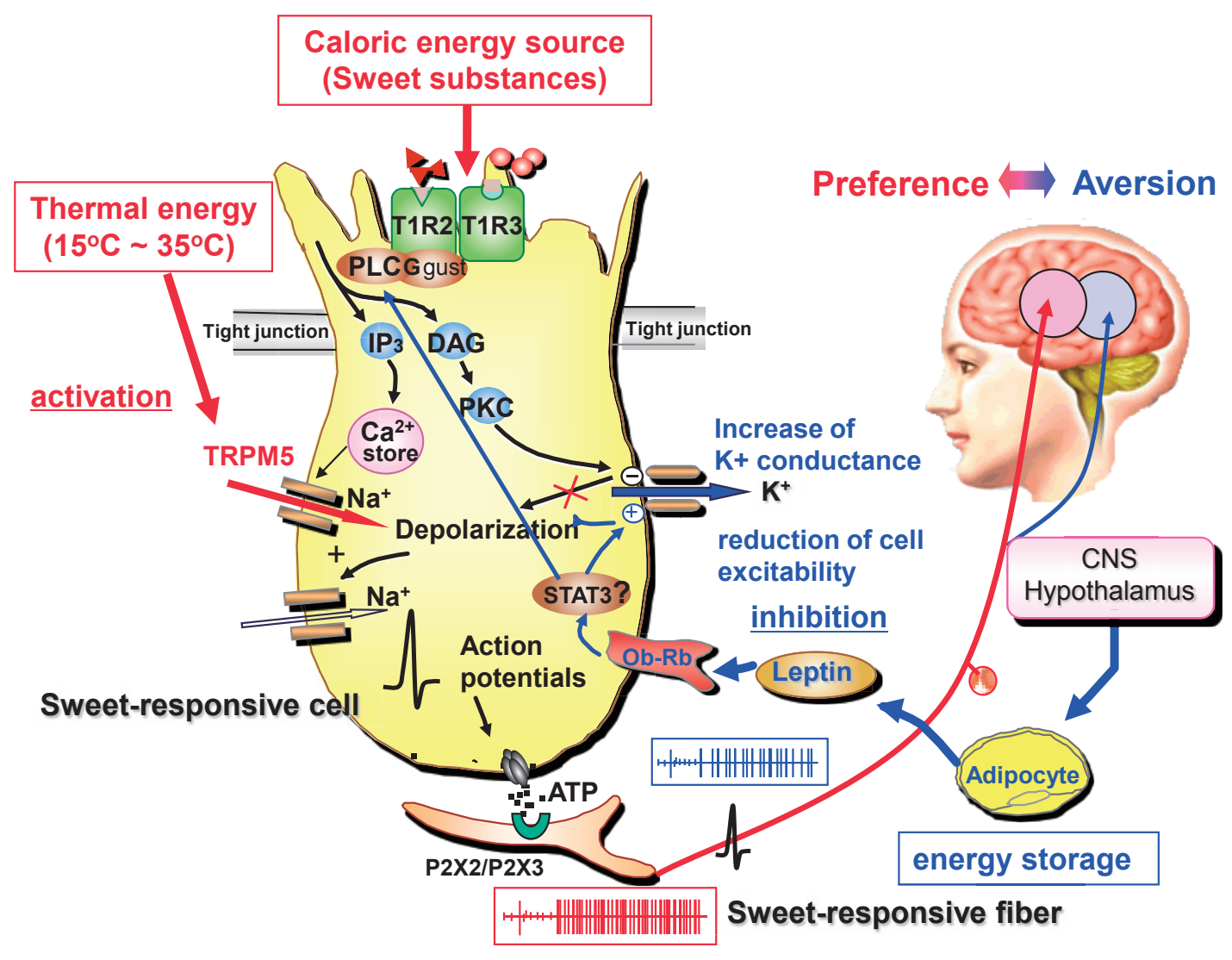

Fig. 1. A schematic drawing of the roles of sweet-sensitive cells in regulation of energy homeostasis. Sweet taste receptor, a heterodimer of T1R2+T1R3, can bind a broad array of sweet compounds including external caloric energy sources. Binding of sweet compounds to T1R2+T1R3 leads to activation and dissociation of the subunits of the coupled heterotrimeric G protein gustducin (Ggust). The dissociated $\beta \gamma$ subunits of the Ggust activate phospholipase C (PLC $\beta 2$ : PLC), which hydrolyzes phosphatidylinositol bisphosphate into diacylglycerol (DAG) and inositol trisphosphate $\left(\mathrm{IP}_{3}\right)$. Release of $\mathrm{Ca}^{2+}$ from intracellular stores activates transient receptor potential cation channel, subfamily M, member 5 (TRPM5) channels, leading to the $\mathrm{Na}^{+}$influx, membrane depolarization, and generation of action potentials. The action potential triggers adenosine 5 '-triphosphate (ATP) release through hemichannels and the released ATP activates purinergic P2X receptors in taste fibers that convey sweet taste information to the brain. TRPM5 channel involved in the transduction of sweet taste acts as a thermosensor $\left(15^{\circ} \mathrm{C}-35^{\circ} \mathrm{C}\right)$. Activation of this channel by temperature, peaking at $35^{\circ} \mathrm{C}$ near body temperature, leads to increase of the sweet sensitivity of the cell. A subset of sweet-sensitive cells also possesses a sensor $(\mathrm{Ob}-\mathrm{Rb})$ for internal energy storage represented by plasma leptin released mainly from the adipose tissue. Increase of plasma leptin level activates leptin receptor, which leads to increase of outward currents, thereby reducing excitability of the cell, followed by reduction of sweet taste information conveyed to the brain. Sweet-sensitive cells may, thus, act as a cell sensor that plays a crucial role on an animal's energy homeostasis. PKC: protein kinase C.

diacylglycerol (DAG) and inositol trisphosphate $\left(\mathrm{IP}_{3}\right)$ (9). Subsequently, $\mathrm{IP}_{3}$ activates the type III $\mathrm{IP}_{3}$ receptor ( $\mathrm{IP}_{3} \mathrm{R} 3$ ), leading to the release of $\mathrm{Ca}^{2+}$ from intracellular stores (10). Rapid increases in $\left[\mathrm{Ca}^{2+}\right]_{\mathrm{i}}$ open basolaterally located transient receptor potential cation channel, subfamily M, member 5 (TRPM5) channels, leading to $\mathrm{Na}^{+}$influx, membrane depolarization, and generation of action potentials $(11,12)$. The action potential triggers adenosine $5^{\prime}$-triphosphate (ATP) release through hemichannels $(13,14)$ and the released ATP activates purinergic $\mathrm{P} 2 \mathrm{X}$ receptors in taste fibers that convey sweet taste information to the brain (15). TRPM5 channel involved in the transduction of sweet taste acts as a thermosensor $\left(15^{\circ} \mathrm{C}-35^{\circ} \mathrm{C}\right)$. Activation of this channel by temperature peaking at $35^{\circ} \mathrm{C}$ near body temperature, leads to increase of the sweet sensitivity of the cell (16).

\section{Sweet sensitivity reduced by increasing internal energy storage}

The functional leptin receptor $(\mathrm{Ob}-\mathrm{Rb})$ is abundantly expressed in several hypothalamic nuclei, which are major target sites for the hormone. However, $\mathrm{Ob}-\mathrm{Rb}$ is also expressed in peripheral organs such as lymph nodes, liver, lung, uterus, adipose tissue, kidney, and pancreas (17). The taste organ has been shown to be 
A

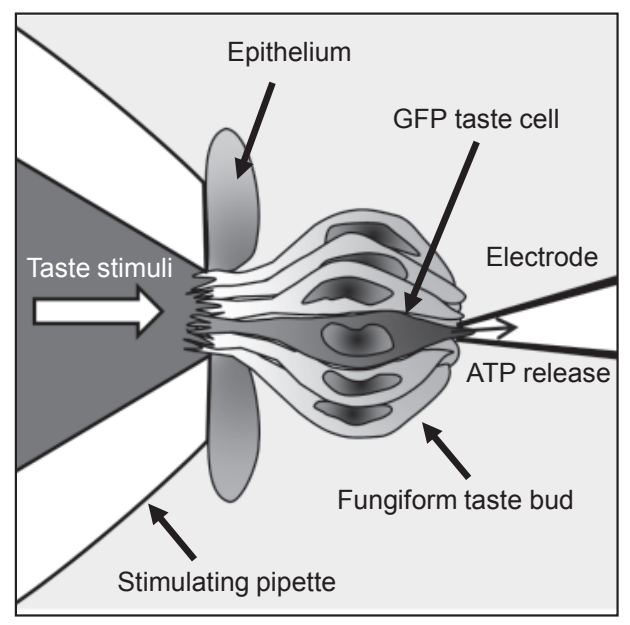

B

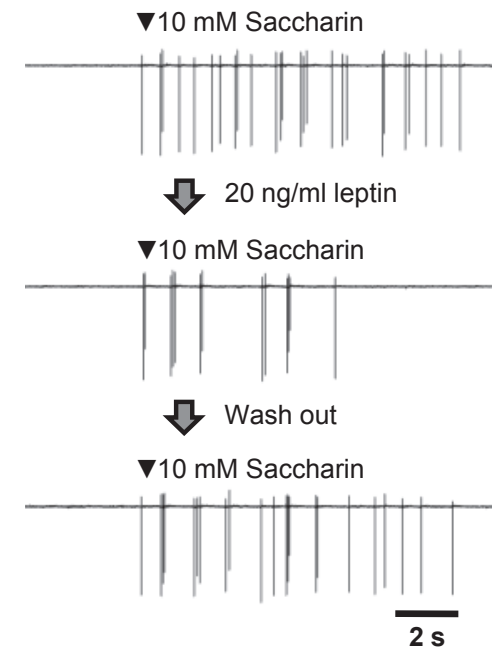

Fig. 2. Leptin inhibition of taste cell responses to saccharin. A: A schematic drawing of the experimental setup for recording of taste cell responses. Taste stimuli were restrictedly applied to the apical side of the isolated taste bud. Leptin was administrated from the basolateral side of the taste bud cell. The recording electrode was applied to the GFP-labeled taste cell (T1R3-GFP, TRPM5-GFP, or gustducin-GFP) from the basolateral side under a laser scanning microscopy. Sweetresponsive cells release ATP depending on the generation of action potentials, and released ATP was collected from the intrapipet solution of the recording electrode. B: Sample recordings demonstrating the effect of bath application of 20 $\mathrm{ng} / \mathrm{ml}$ leptin on responses of a taste cell to $10 \mathrm{mM}$ saccharin. Bath application of leptin suppressed the saccharin response of the cell. After wash-out of leptin, the saccharin response was recovered to the control level. another peripheral target for leptin. The hormone directly acts on taste receptor cells via Ob-Rb expressed in these cells and it specifically inhibits peripheral gustatory neural and behavioral responses to sweet substances without affecting responses to sour, salty and bitter substances in lean mice. The strength of suppressive effects by leptin was at most about $30 \%$ of control responses, and the effect may saturate when plasma leptin concentration reaches about $15-20 \mathrm{ng} / \mathrm{ml}(5,6)$. It was also revealed that outward currents of isolated taste bud cells in response to depolarizing voltage steps were increased during bath application with leptin to the cells. Such selective inhibition of sweet taste responses by leptin was not observed in leptin receptor-deficient $d b / d b$ mice $(5-7)$. We recently developed a loose patch configuration to record taste responses from single cells of taste buds isolated from the fungiform papilla (Fig. 2A) (18). In this system, taste stimulation can be applied restrictedly to the apical side of the taste cell membrane and action potentials of the cell to the stimulation can be recorded from the basolateral side of the taste cell (18). By using this recording system, we examined leptin effects on taste responses of taste receptor cells. As shown in Fig. 2B, impulse frequency of a single taste bud cell in response to saccharin $\mathrm{Na}$ was substantially reduced during bath application of $20 \mathrm{ng} / \mathrm{ml}$ leptin to the basolateral membrane of the cell and recovered after wash-out of leptin. About $50 \%$ (8 out of 16) of sweet-responsive taste cells showed such leptin inhibition of spike frequencies (R. Yoshida et al., unpublished observation). These results suggest that leptin may be a sweet taste modulator that may take part in the regulation of food intake. However, little is known about potential links between leptin and sweet taste in humans.

\section{Leptin and sweet taste in humans}

It has been shown in both rats and humans that there is a diurnal pattern in circulating leptin levels $(19,20)$. In humans, leptin levels start rising before noon and peak between 23:00 $\mathrm{h}$ and 01:00 h, after which the levels decline until morning (21). Frequent blood sampling revealed that plasma leptin levels are pulsatile, with approximately 30 pulses in $24 \mathrm{~h}$, but without a clear relation to meals $(21,22)$. However, several studies have also demonstrated meal-related shifts in the diurnal pattern of plasma leptin. For example, when meals were shifted by $6.5 \mathrm{~h}$ without changing the light or sleep cycles in humans, the plasma leptin levels were similarly shifted by $5-7 \mathrm{~h}$ (23). The nocturnal rise of leptin does not occur if the subjects are fasted (24). If leptin acts as a modulator for sweet taste sensitivity, and it shows diurnal variation, then it follows that the threshold for sweet taste may show correlated diurnal variation.

To examine this possibility, we measured recognition thresholds of non-obese subjects (BMI < 25) for various taste stimuli and plasma leptin levels at several times during the day under normal meal conditions with 3 meals and restricted meal conditions with 1 or 2 meals per day (25). In the normal feeding condition, leptin concentrations started rising before noon and peaked in the night. This rise in leptin occurred later in the 2 and 
1 meal conditions, resulting in a phase shift of diurnal variation. With regard to taste recognition thresholds, similar to plasma leptin levels, significant time-dependent increases in thresholds for sucrose, glucose, and saccharin were observed in the normal meal condition (25). That is, subjects needed higher concentrations of these sweeteners to detect the stimulus quality when they were tested in the evening compared to the morning. There was also a phase shift in 1 or 2 meal conditions, eliminating the time-dependent changes in sweetener recognition threshold. Diurnal variations in sweetener thresholds were significantly different among the 3 meal conditions. This diurnal variation is sweet-taste selective: it was not observed in thresholds for other taste stimuli $(\mathrm{NaCl}$, citric acid, quinine, and mono-sodium glutamate) (25). Recently, we measured recognition thresholds of obese subjects $(\mathrm{BMI}>25)$ for sweet compounds and plasma leptin levels at several times during the day under normal meal conditions with 3 meals and found that the diurnal variations for sweet recognition thresholds disappeared in the obese subjects (K. Sanematsu et al., unpublished observation). Mean plasma leptin level of the obese subjects in the morning was already about $20 \mathrm{ng} / \mathrm{ml}$, which may be around the saturation level of the leptin effect in mice (about $15-20 \mathrm{ng} / \mathrm{ml}$ ) (5). Therefore, lack of diurnal variation for sweet recognition thresholds in obese subjects may be due to their higher basal plasma leptin levels.

\section{Potential links among sweet taste sensitivity, plasma leptin, blood glucose, and plasma insulin}

The above-mentioned study also demonstrated that blood glucose and plasma insulin levels of non-obese subjects showed meal-related changes with increases evident after each meal in the 3 different feeding conditions. Moreover, increases in blood glucose after the first meal in the 1- and 2-meal conditions were higher than that in the normal, 3-meal feeding condition. Similar tendency was observed in case of plasma insulin levels. The diurnal variation for sweet thresholds in the normal feeding condition ( 3 meals) was independent of the meal timing and thereby independent of blood sugar and plasma insulin levels (25). However, it is interesting to note that post-ingestive rises of blood glucose and insulin levels of individuals after a meal were negatively correlated with leptin levels and recognition thresholds for sucrose before a meal (25). This suggests that greater post-ingestive rises of blood glucose and insulin levels may be associated with lower leptin levels and higher sweet sensitivities before a meal.

With regards to this linkage, a previous study reported that oral stimulation with sucrose, but not $\mathrm{NaCl}$, elicits an increase in activities of the pancreatic branch of the vagal nerve in rats (26). This response occurs about 5 min after onset of the stimulation and lasts for at least 30 min. Since the so-called cephalic-phase insulin release (CPIR) is known to occur as early as $1-4$ min after food ingestion (27), the late response observed in the vagal efferent nerve to oral stimulation with sucrose should not relate to the CPIR but may be involved in factors related to post-ingestive insulin release. In addition, recent studies demonstrated that enteroendocrine cells in the gastrointestinal tract express sweet receptors (T1R2+T1R3) and leptin receptors, and they release glucagon-like peptide-1 in response to sugars and nonnutritive sweeteners. This leads to an increase of expression of $\mathrm{Na}^{+} /$glucose co-transporter SGLT1, followed by increased glucose absorption in enterocytes (28). Our recent study demonstrated that enteroendocrine cells, like taste cells, exhibited decreases in response to sweet compounds with increasing leptin concentration (M. Jyotaki et al., unpublished observation). This suggests a possibility that enteroendocrine cells may also possess comparable sweet sensitivities with diurnal variations parallel with plasma leptin levels and meal-related phase shifts. If this is the case, post-ingestive rises in glucose and insulin levels may be influenced by sweet sensitivities of both taste and gut cells (25).

This paper summarized the data from recent mouse and human studies that addressed leptin modulation on sweet taste responses $(5-7,25)$. The data from human studies indicate that the taste recognition threshold of non-obese humans for sweet compounds have a diurnal variation that parallels that for leptin levels, being lowest in the morning and highest at night. When leptin levels were phase-shifted following imposition of 1 or 2 meals per day, the diurnal variation of thresholds for sweet sugars shifted in parallel (25). This synchronization of diurnal variation in leptin levels and sweet taste recognition thresholds suggest a mechanistic connection between these two variables. This linkage between the leptin levels and responsiveness to sweet compounds may be comparable with those found in mouse taste cells in the oral cavity $(5-7)$ and the gut (28). Thus, leptin may act as a modulator of sweet taste responses in mammals, having a role in maintaining energy homeostasis.

\section{Acknowledgments}

This work was supported by Grant-in-Aids 18109013 and 1807704 (Y.N.) for Scientific Research from Japan Society for the Promotion of Science. 


\section{References}

1 Chandrashekar J, Mueller KL, Hoon MA, Adler E, Feng L, Guo W, et al. T2Rs function as bitter taste receptors. Cell. 2000;100:703-711.

2 Nelson G, Hoon MA, Chandrashekar J, Zhang Y, Ryba NJ, Zuker CS. Mammalian sweet taste receptors. Cell. 2001;106:381-390.

3 Zhang Y, Proenca R, Maffei M, Barone M, Leopold L, Friedman JM: Positional cloning of the mouse obese gene and its human homologue. Nature. 1994;372:425-432.

4 Halaas JL, Gajiwala KS, Maffei M, Cohen SL, Chait BT, Rabinowitz D, et al. Weight-reducing effects of the plasma protein encoded by the obese gene. Science. 1995;269:543-546.

5 Kawai K, Sugimoto K, Nakashima K, Miura H, Ninomiya Y. Leptin as a modulator of sweet taste sensitivities in mice. Proc Natl Acad Sci U S A. 2000;97:11044-11049.

6 Ninomiya Y, Shigemura N, Yasumatsu K, Ohta R, Sugimoto $\mathrm{K}$, Nakashima K, et al. Leptin and sweet taste. Vitam Horm. 2002; 64:221-248.

7 Shigemura N, Ohta R, Kusakabe Y, Miura H, Hino A, Koyano $\mathrm{K}$, et al. Leptin modulates behavioral responses to sweet substances by influencing peripheral taste structures. Endocrinology. 2004;145:839-843.

8 Wong GT, Gannon KS, Margolskee RF. Transduction of bitter and sweet taste by gustducin. Nature. 1996;381:796-800.

9 Margolskee RF. Molecular mechanisms of bitter and sweet taste transduction. J Biol Chem. 2002;277:1-4.

10 Hisatsune C, Yasumatsu K, Takahashi-Iwanaga H, Ogawa N, Kuroda Y, Yoshida R, et al. Abnormal taste perception in mice lacking the type 3 inositol 1,4,5-trisphosphate receptor. J Biol Chem. 2007;282:37225-37231.

11 Huang L, Rong M, Kozak JA, Preuss AK, Zhang H, Max M, et al. A transient receptor potential channel expressed in taste receptor cells. Nat Neurosci. 2002;5:1169-1176.

12 Medler KF, Margolskee RF, Kinnamon SC. Electrophysiological characterization of voltage-gated currents in defined taste cell types of mice. J Neurosci. 2003;23:2608-2617.

13 Huang YJ, Maruyama Y, Dvoryanchikov G, Pereira E, Chaudhari $\mathrm{N}$, Roper SD. The role of pannexin 1 hemichannels in ATP release and cell-cell communication in mouse taste buds. Proc Natl Acad Sci U S A. 2007;104:6436-6441.

14 Romanov RA, Rogachevskaja OA, Bystrova MF, Jiang P, Margolskee RF, Kolesnikov SS. Afferent neurotransmission mediated by hemichannels in mammalian taste cells. EMBO J. 2007;26:657-667.
15 Finger TE, Danilova V, Barrows J, Bartel DL, Vigers AJ, Stone $\mathrm{L}$, et al. ATP signaling is crucial for communication from taste buds to gustatory nerves. Science. 2005;310:1495-1499.

16 Talavera K, Yasumatsu K, Voets T, Droogmans G, Shigemura N, Ninomiya $Y$, et al. Heat activation of TRPM5 underlies thermal sensitivity of sweet taste. Nature. 2005;438:1022-1025.

17 Flier JS. Obesity wars: molecular progress confronts an expanding epidemic. Cell. 2004;116:337-350.

18 Yoshida R, Shigemura N, Sanematsu K, Yasumatsu K, Ishizuka S, Ninomiya Y. Taste responsiveness of fungiform taste cells with action potentials. J Neurophysiol. 2006;96:3088-3095.

19 Saladin R, Vos DP, Guerre-Millo M, Leturque A, Girard J, Staels $\mathrm{B}$, et al. Transient increase in obese gene expression after food intake or insulin administration. Nature. 1995;377:527-529.

20 Ahima RS, Prabakaran D, Mantzoros C, Qu D, Lowell B, Maratos-Flier E, et al. Role of leptin in the neuroendocrine response to fasting. Nature. 1996;382:250-252.

21 Sinha MK, Sturis J, Ohannesian J, Magosin S, Thomas S, Heiman $\mathrm{ML}$, et al. Ultradian oscillations of leptin secretion in humans. Biochem Biophys Res Commun. 1996;228:733-738.

22 Licinio J, Mantzoros C, Negrao AB, Cizza G, Wong ML, Bongiorno $\mathrm{PB}$, et al. Human leptin levels are pulsatile and inversely related to pituitary-adrenal function. Nat Med. 1997;3:575-579.

23 Schoeller DA, Cella LK, Sinha MK, Caro JF. Entrainment of the diurnal rhythm of plasma leptin to meal timing. J Clin Invest. 1997;100:1882-1887.

24 Boden G, Chen X, Mozzoli M, Ryan I. Effect of fasting on serum leptin in normal human subjects. J Clin Endocrinol Metab. 1996;81:3419-3423.

25 Nakamura Y, Sanematsu K, Ohta R, Shirosaki S, Koyano K, Nonaka K, et al. Diurnal variation of human sweet taste recognition thresholds is correlated with plasma leptin level. Diabetes. 2008;57:2661-2665.

26 Niijima A. Effects of taste stimulation on the efferent activity of the pancreatic vagus nerve in the rat. Brain Res Bull. 1991;26:165-167.

27 Teff KL, Mattes RD, Engelman K.Cephalic phase insulin release in normal weight males: verification and reliability. Am J Physiol. 1991;261:E430-E436.

28 Margolskee RF, Dyer J, Kokrashvili Z, Salmon KSH, Ilegems E, Daly K, et al. T1R3 and gustducin in gut sense sugars to regulate expression of $\mathrm{Na}^{+}$-glucose cotranspoter 1. Proc Natl Acad Sci U S A. 2007;104:15075-15080. 